\title{
JEVTM 10th Edition
}

\author{
Tal M Hörer \\ Editor in Chief JEVTM
}

Four years ago, a group of enthusiastic physicians established the Journal of Endovascular Resuscitation and Trauma Management, JEVTM [1,2] (www.jevtm.com). The need for a professional, peer-reviewed platform for endovascular and hybrid methods of resuscitation and trauma has increased over the last decade as new methods have become established in the field [3]. The development of multidisciplinary teamwork and new technologies in endovascular therapy and imaging has made it possible to treat patients using minimally invasive methods and potentially decrease the morbidity and mortality of both trauma and non-trauma patients [4,5].

In parallel, the Endovascular Resuscitation and Trauma Management (EVTM) platform has developed through scientific publications in high-impact journals, manuals, textbooks, workshops, symposia, and the EVTM society [3,6,7]. These developments have increased in recent years and are reflected in the submission rate (and also the rejection rate) of the JEVTM as well as interest in collaboration with other international established medical societies (trauma, vascular, radiology, intensive care, emergency medicine, and military).

The fact is that the surgical and non-surgical treatments of many patient groups have changed in recent decades, significantly in favor of the use of endovascular methods. Examples of some well-documented disorders are: ruptured abdominal aneurysm and the need for endovascular aortic repair, blunt thoracic aortic injuries, embolization in the spleen and other visceral organs, and bleeding or pelvic bleeding in trauma [8-10]. We believe that use of the EVTM concept, which covers all

\section{Corresponding author:}

Tal M Hörer, Department of Cardiothoracic and Vascular Surgery and Dept of Surgery, Faculty of Medicine and Health, Örebro University, Örebro University Hospital, 70185 Örebro, Sweden. Email: tal.horer@regionorebrolan.se

(C) 2021 CC BY 4.0 - in cooperation with Depts. of Cardiothoracic/ Vascular Surgery, General Surgery and Anesthesia, Örebro University Hospital and Örebro University, Sweden these conditions, methods and their applications, and even some others, can, in multidisciplinary efforts, save more patients. This concept can be used in both developed and less-developed countries, in highly sophisticated hybrid suites with state-of-the-art technology and in austere or military environments [11]. The potential of EVTM is huge and covers both bleeding and non-bleeding patients at the early phase of intervention and during resuscitation. This includes trauma-induced hemodynamically unstable patients ; non-trauma bleeders; patients with gastrointestinal, post-partum or other types of bleeding; potentially patients with cardiac arrest; and other patient groups. Considering the high mortality and morbidity of patients who go through resuscitation, there is a very important place for research and clinical development in the field of EVTM $[3,12]$. The JEVTM aims to share data and clinical experiences to spread this news.

In the last nine editions of the journal, more than 120 peer-reviewed papers presented scientific developments in the field of EVTM. In this forthcoming $10^{\text {th }}$ edition, we hope to present more scientific and clinical data to encourage our readers to develop EVTMrelated clinical and experimental research that might benefit our patients. A shift from a great interest in Resuscitative Balloon Occlusion of the Aorta (REBOA) previously to other diverse endovascular and hybrid methods for bleeding control and resuscitation becomes clear when reading the last nine editions of JEVTM. Over time, more high-quality articles have been submitted and the journal is developing with every issue. The editorial board and editors work clinically and are established researchers in the field. Trauma and vascular surgeons, interventional radiologists, intensive care and emergency doctors, and prehospital experts are all dedicated to developing the field of EVTM and making the JEVTM an established medical journal. JEVTM is indexed in Scopus and Web-of-Science, and we hope that it will be indexed soon in other well-established systems so it can well serve our readers. The JEVTM is free online and is the official journal of the EVTM Society. 
Lastly, we would like to thank our former editor, Jonathan Morrison; leading editors, Joe DuBose, Megan Brenner and Yosuke Matsumura; associate editor, Boris Kessel; senior advisor, Ernest E Moore; as well as the editorial technical team and the Örebro University Hospital research division. The work of our reviewers should also be acknowledged as well as their contributions to the critical revision of all articles published in the JEVTM.

We hope the next edition of the JEVTM will be of great value to our readers and that it will continue to grow as a true scientific platform for EVTM.

\section{REFERENCES}

[1] DuBose J. The Journal of Endovascular Resuscitation and Trauma Management: a timely endeavor. J Endovasc Resusc Trauma Manag. 2017;1(1):1-2.

[2] Brenner ML. Introduction to the Second Edition of JEVTM. J Endovasc Resusc Trauma Manag. 2018;2(1):1.

[3] Horer T. Resuscitative endovascular balloon occlusion of the aorta (REBOA) and endovascular resuscitation and trauma management (EVTM): a paradigm shift regarding hemodynamic instability. Eur J Trauma Emerg Surg. 2018;44(4):487-9.

[4] Mayer D, Aeschbacher S, Pfammatter T, et al. Complete replacement of open repair for ruptured abdominal aortic aneurysms by endovascular aneurysm repair: a two-center 14-year experience. Ann Surg. 2012;256(5): 688-96.
[5] McGreevy DT, Horer TM. Treatment of aortic aneurysms during the COVID-19 pandemic: time to abandon the NICE guidelines. J Endovasc Ther. 2020;27(6): 979.

[6] Hörer TM MJ, DuBose JJ, Reva VA, et al. Top stent manual, The art of EndoVascular hybrid Trauma and bleeding Management. 1st ed. Hörer T, editor. Örebro, Sweden: Örebro University Hosptial; 2017.

[7] Horer TM, Pirouzram A, Khan M, et al. Endovascular Resuscitation and Trauma Management (EVTM) - Practical Aspects and Implementation. Shock. 2020.

[8] Faulconer ER, Branco BC, Loja MN, et al. Use of open and endovascular surgical techniques to manage vascular injuries in the trauma setting: a review of the American Association for the Surgery of Trauma Prospective Observational Vascular Injury Trial registry. J Trauma Acute Care Surg. 2018;84(3):411-7.

[9] Coccolini F, Stahel PF, Montori G, et al. Pelvic trauma: WSES classification and guidelines. World J Emerg Surg. 2017;12:5.

[10] Coccolini F, Montori G, Catena F, et al. Splenic trauma: WSES classification and guidelines for adult and pediatric patients. World J Emerg Surg. 2017;12:40.

[11] Reva VA, Horer TM, Makhnovskiy AI, Sokhranov MV, Samokhvalov IM, DuBose JJ. Field and en route resuscitative endovascular occlusion of the aorta: a feasible military reality? J Trauma Acute Care. 2017;83: S170-S6.

[12] Khan MA, Cotton B, Horer T, Duschesne J. DCR and EVTM: the future of trauma research and training. J Endovasc Resusc Trauma Manag. 2020;4(2):75-6. 